\title{
Management of pulmonary hernia through a flail segment in closed thoracic trauma using open reduction, internal fixation and pectoralis major flap reconstruction: A case report
}

\author{
Steven T Lanier BA BS ${ }^{1}$, Meredith Wetterau MD², Eduardo Smith-Singares MD ${ }^{3}$, Thomas Bilfinger MD ${ }^{4}$, \\ James Vosswinkel MD ${ }^{3}$, Marc J Shapiro MD ${ }^{3}$, Alexander B Dagum MD FRCSC ${ }^{5}$
}

ST Lanier, M Wetterau, E Smith-Singares, et al. Management of pulmonary hernia through a flail segment in closed thoracic trauma using open reduction, internal fixation and pectoralis major flap reconstruction: A case report. Can J Plast Surg 2011;19(4):145-147.

The present article reports on the successful management of a large flail chest with traumatic pulmonary herniation in a patient who could not be weaned from mechanical ventilation following a course of conservative management. Surgical intervention involved open reduction and internal fixation with tubular plates to stabilize the flail segment, followed by a pectoralis major myocutaneous flap to repair the chest wall defect. Following surgical intervention, the patient was able to be weaned from mechanical ventilation and showed remarkable improvement in pulmonary function parameters. To the authors' knowledge, the present report is the first to describe the use of open reduction and internal fixation of the chest wall and flap reconstruction to treat lung herniation with a flail chest segment.

Key Words: Flail chest; Pectoralis major myocutaneous flap; Pulmonary herniation

B lunt trauma resulting in flail chest with subcutaneous lung herniBation is an exceedingly rare clinical finding. We report on the successful management of a large flail chest with traumatic pulmonary herniation in a patient with previous left chest irradiation for breast cancer. This was accomplished using open reduction and internal fixation (ORIF) with tubular plates to stabilize a large flail segment and a pectoralis major myocutaneous flap to repair the chest wall defect. To our knowledge, the present report is the first to describe using ORIF of the chest wall and flap reconstruction to treat lung herniation with a flail chest segment.

\section{CASE PRESENTATION}

A 57-year-old woman with a history of left breast lumpectomy, axillary node dissection and radiation therapy of her breast was a restrained backseat passenger involved in a head-on motor vehicle collision. On primary survey in the emergency room, the patient was normotensive and tachycardic with complaints of chest pain and shortness of breath. A left flail chest deformity was noted with decreased breath sounds on the left, and the patient was subsequently intubated due to concern for impending respiratory failure. She was noted to have a Glasgow Coma Scale score of 15 following intubation. Bilateral chest tubes were placed. A chest $\mathrm{x}$-ray revealed multiple left-sided rib fractures, a fracture at the sternoclavicular junction, and a left pneumothorax (Figure 1). Subsequently, a computed tomography scan of the chest demonstrated pneumomediastinum
La prise en charge d'une hernie pulmonaire par le segment costal d'un traumatisme thoracique fermé au moyen d'une réduction ouverte, d'une fixation interne et de la reconstruction par lambeau du grand pectoral : un rapport de cas

Le présent article rend compte de la prise en charge réussie d'une importante herniation traumatique du volet costal du poumon chez un patient qui ne pouvait être sevré d'une ventilation mécanique après la durée d'un traitement classique. L'intervention chirurgicale a inclus une réduction ouverte et une fixation interne à l'aide de plaques tubulaires en vue de stabiliser le segment costal, ainsi que d'un lambeau myocutané du grand pectoral pour réparer l'anomalie de la paroi thoracique. Après l'intervention chirurgicale, le patient a pu être sevré de la ventilation mécanique et a démontré une remarquable amélioration des paramètres de la fonction pulmonaire. En autant que le sache les auteurs, le présent rapport est le premier à décrire le recours à une réduction ouverte, à une fixation interne de la paroi thoracique et à une reconstruction par lambeau pour traiter une herniation pulmonaire au moyen d'un segment costal du thorax.

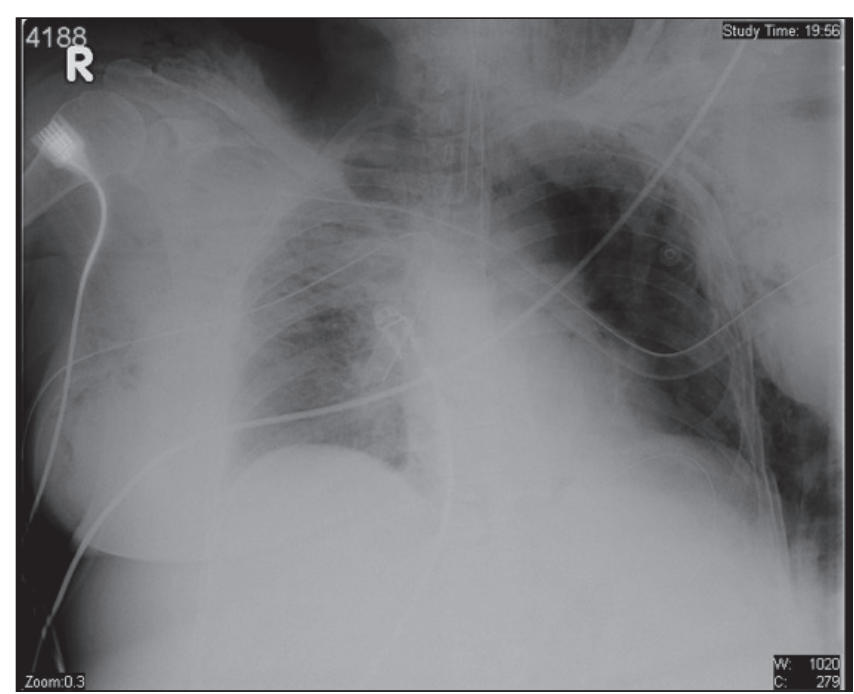

Figure 1) Chest $x$-ray showing multiple rib fractures and disruption of the left sternocostal junction

with subcutaneous emphysema, bilateral pulmonary contusions, and disruption of the left chest wall with sternal costochondral fractures and lung herniation (Figure 2).

${ }^{1}$ School of Medicine, Stony Brook University Medical Center, Stony Brook; ${ }^{2}$ Department of Surgery, New York University Medical Center,

New York; ${ }^{3}$ Department of Surgery, Division of Trauma and Surgical Critical Care; ${ }^{4}$ Department of Surgery, Division of Cardiothoracic

Surgery; ${ }^{5}$ Department of Surgery, Division of Plastic and Reconstructive Surgery, Stony Brook, New York, USA

Correspondence: Dr Alexander B Dagum, Health Sciences Center T19 Room 060, Stony Brook, New York 11794-8191, USA.

Telephone 631-444-8210, fax 631-444-6007, e-mail adagum@notes.cc.sunysb.edu 


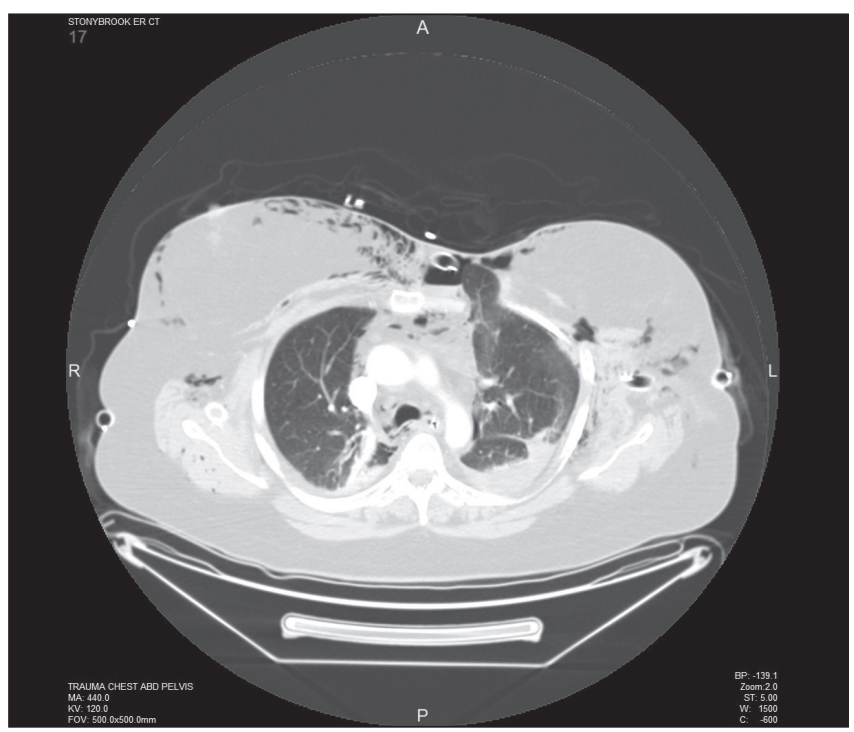

Figure 2) Computed tomography showing pneumomediastinum, subcutaneous emphysema, and disruption of the chest wall with lung herniation

The patient was transferred to the surgical intensive care unit, where she remained ventilator dependent, requiring a tracheostomy. Due to an inability to wean the patient from mechanical ventilation after three weeks, ORIF of the ribs and sternum was performed to repair her left flail segment. Intraoperatively, a $25 \mathrm{~cm} \times 3 \mathrm{~cm}$ area of soft tissue and skin was excised, revealing the underlying subcutaneous herniated lung with laceration secondary to the sternal and rib disruptions (Figure 3B). Exposure of the ribs and sternum revealed a $12 \mathrm{~cm} \times 20 \mathrm{~cm}$ disruption of the chest wall. The devitalized lung was resected, and the remaining lung reduced into the left hemithorax. The chest cage was reconstructed and stabilized with two $3.5 \mathrm{~cm} \times 0.25 \mathrm{~cm} \mathrm{12-hole} \mathrm{plates} \mathrm{extending}$ across ribs five to eight. Open reduction and stabilization of the fifth rib onto the sternum was accomplished with a 10-hole, one-third tubular plate. The sternal clavicular fracture was reduced and stabilized with an eight-hole, one-third tubular plate across the clavicle onto the sternum and rib, which secured the superior segment. Four millimetre cancellous screws were used (Figure 3C).

Closure of the chest wall defect and coverage of the exposed plates was achieved via a left pectoralis major myocutaneous flap. With an incision from the inframammary crease to the anterior axillary line, the pectoralis major was detached inferiorly and medially, and based on the thoracoacromial vessels. The flap was rotated and advanced as a unit to close the $25 \mathrm{~cm} \times 5 \mathrm{~cm}$ defect and cover the plates, screws and previously radiated ribs.
The patient tolerated the procedure well, with an improvement in respiratory status, allowing her to be weaned off the ventilator over three weeks postoperatively and ultimately decannulated of her tracheostomy. The plated fractured ribs continued to heal over the ensuing months. Four months postoperatively, the loosening of a screw led to the development of an infection with a sinus tract in the mid portion of the incision. Removal of the screw and hardware, and a short course of antibiotics led to rapid resolution of the infection and tract (Figure 4). At nine months follow-up, formal pulmonary function testing revealed remarkably improved parameters (Table 1 ).

\section{DISCUSSION}

While the first description of protrusion of chest contents secondary to trauma can be traced to 1250 (1), the first clinical description of pulmonary herniation was provided by Roland in 1499 (2). In 1847, Morel-Lavelle (3) performed the first comprehensive review, classifying lung parenchymal herniations according to etiology. Since these seminal works, sporadic descriptions have appeared in the literature (4-7), totaling fewer than 300 reported cases (8).

Pulmonary hernias are divided into two groups: congenital (18\% of reported cases) and acquired (82\%) (9). Acquired cases can be further subdivided according to the mechanism producing them (spontaneous or traumatic) or the location of the hernia defect (cervical, intercostal, parasternal or transdiaphragmatic) $(10,11)$.

Cervical lung herniation is believed to represent a defect of Sibson's fascia. Although uncommon overall (12), it is most frequently diagnosed in children and is three times more likely to occur on the right side (13). Although surgical therapy is usually recommended (14), observation and expectant management are frequently prescribed (15) because many tend to disappear with time. Transdiaphragmatic herniation is the rarest type, with fewer than 10 reported cases (10).

Parasternal and intercostal hernias of a spontaneous nature have been described (16), but are most frequently observed in the context of trauma, and account for up to $80 \%$ of acquired cases (17). The mechanism by which herniation of lung parenchyma through a chest wall defect occurs has been described as part of the seatbelt syndrome (18). Disruption of the costochondral junction due to rapid deceleration, in combination with multiple rib fractures after blunt trauma, can occur in an individual using a three-point restraint seatbelt (6).

Pulmonary herniation in conjunction with a flail chest segment is an even rarer phenomenon. Diagnosis of a flail chest segment relies on the physical examination finding of paradoxical motion of the segment during spontaneous respiration, and is confirmed by visualization of fractures in at least three adjacent ribs in two places on chest $\mathrm{x}$-ray or computed tomography scan (19). Imaging studies will demonstrate concurrent lung herniation, if present. In the absence of a flail segment, lung herniation presents as a well-circumscribed bulge from the chest wall that expands on inspiration and Valsalva manoeuvre (8).
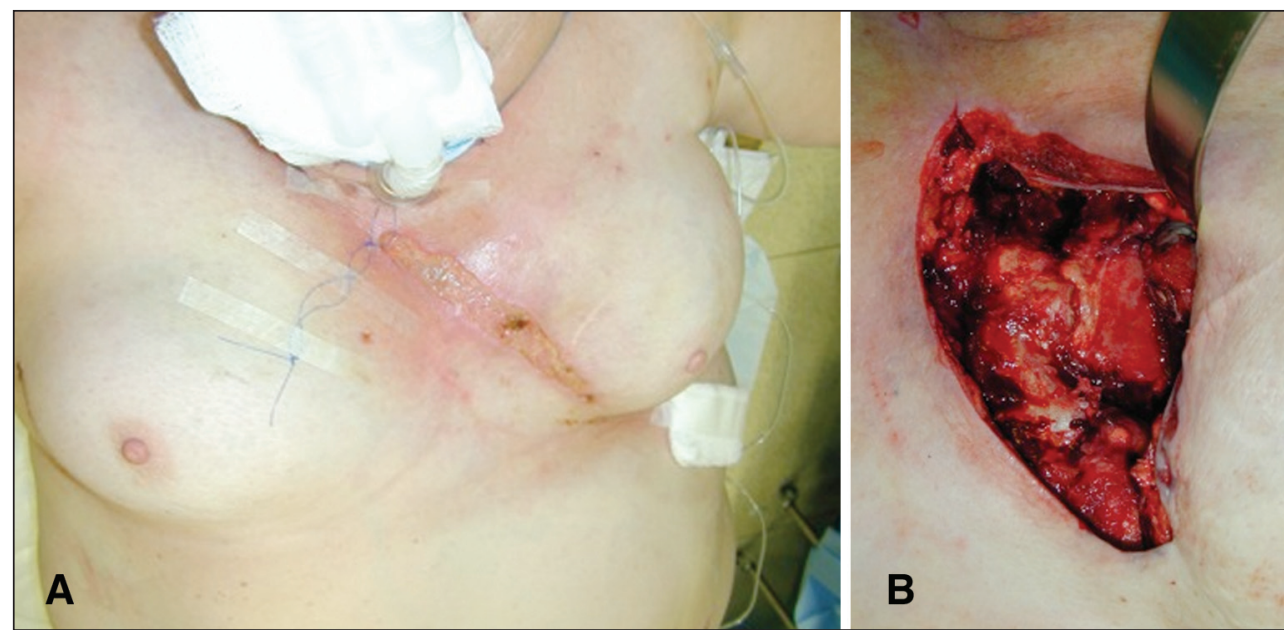

B

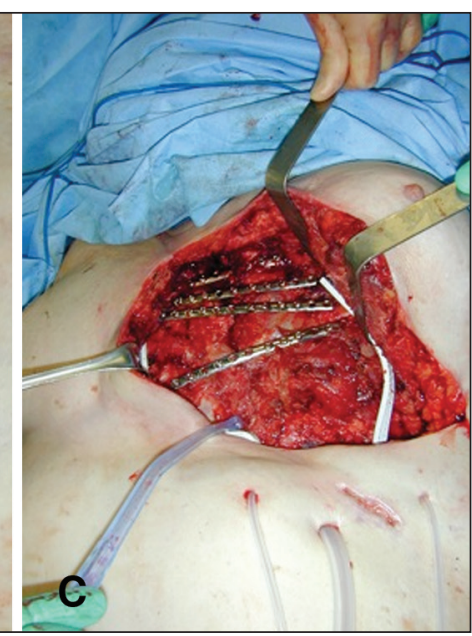

Figure 3) A Preoperative photograph. B Intraoperative photograph, before repair. C Intraoperative photograph, following repair of the flail segment 


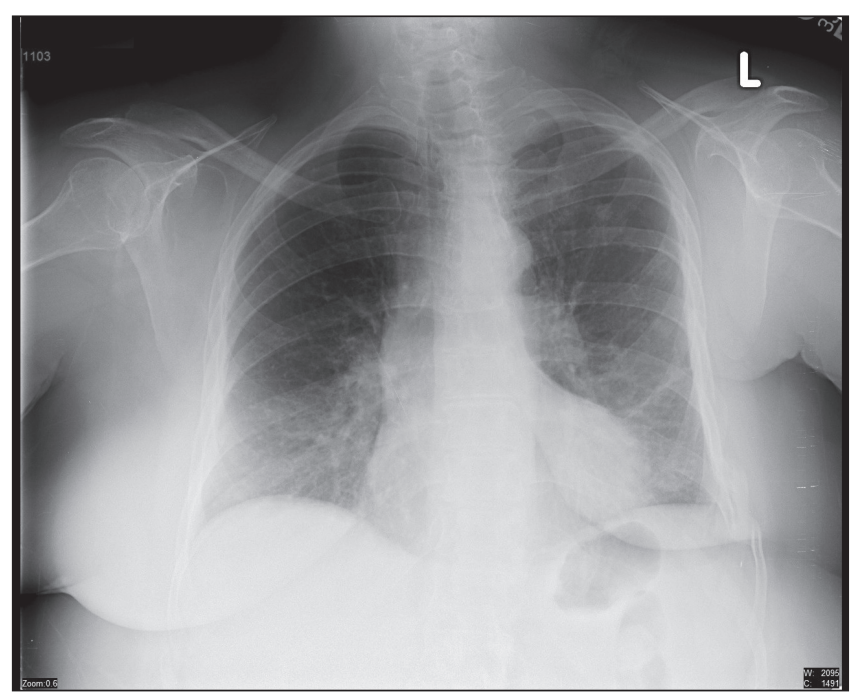

Figure 4) Chest $x$-ray following hardware removal showing healed fractures

At our institution, the preferred treatment for large flail chest segments in ventilated patients who are difficult to wean from a ventilator is ORIF of the chest wall. This has generally led to a more rapid extubation and faster recovery than traditional conservative measures such as internal pneumatic stabilization. While there has been controversy in the past regarding the relative merits of surgical treatment versus more conservative management, current evidence associates surgical fixation of flail chest with decreased time on mechanical ventilation, fewer days in the intensive care unit, lower rates of posttraumatic pneumonia, lower mortality rates and a higher rate of return to full-time employment by six months after injury (20-22). Furthermore, while pulmonary contusion, rather than the flail segment itself, is the main indication for mechanical ventilation, surgical fixation can prevent further pulmonary injury from fractured ribs and help alleviate pain, with a reduced need for analgesia $(20,23)$.

Surgical intervention was necessary in this patient due to significant pulmonary exposure and an inability to wean from mechanical ventilation following a three-week trial of conservative management. Although small pulmonary herniations may resolve spontaneously, the majority require surgical reduction (24). Traditional surgical treatment would have consisted of debridement, reduction of the lung, and repair using a large prosthetic mesh sutured from the ribs to the sternum (25) with myocutaneous flap coverage. While such treatment would repair the pulmonary hernia, it would leave the patient with a large semi-flail component, with both acute and chronic effects on pulmonary mechanics $(19,26)$. Furthermore, this patient's large anterior subcutaneous lung herniation and flail chest segment were complicated by overlying devitalized radiated skin (Figure 3A) and underlying radiated tissue, which increases the infective risk associated with the use of a prosthetic mesh.

For the above reasons, we chose to reconstruct the chest wall using tubular plates, which not only repaired the flail chest, but also maintained the lung reduced to an anatomical chest wall cavity. The loss of skin and subcutaneous tissue with exposure of the fractured ribs hardware and sternum necessitated coverage, and the pectoralis major myocutaneous flap provided for stable coverage with an excellent blood supply. This procedure afforded the patient a short postoperative duration of mechanical ventilation, rapid healing of previously radiated ribs and a better long-term functional outcome. To our knowledge, the present report constitutes the first description of this technique for this indication.

NOTE: This work originated at Stony Brook University Medical Center, Stony Brook, New York 11794, USA.
TABLE 1

Lung volume parameters at nine months postoperatively

\begin{tabular}{|c|c|c|c|}
\hline \multirow[b]{2}{*}{ Parameter } & \multirow[b]{2}{*}{ Predicted } & \multicolumn{2}{|c|}{ Predrug } \\
\hline & & Measured & Predicted, \% \\
\hline IC & 2.03 & 2.13 & 105 \\
\hline ERV & 1.02 & 0.55 & 54 \\
\hline VC & 3.05 & 2.69 & 88 \\
\hline RV & 1.83 & 1.24 & 68 \\
\hline TLC & 4.88 & 3.93 & 81 \\
\hline FRC & 2.85 & 1.79 & 63 \\
\hline $\mathrm{FEV}_{1}$ & 2.53 & 2.15 & 85 \\
\hline $\mathrm{FEV}_{1} / \mathrm{FVC}$ & 83.00 & 82.00 & 99 \\
\hline
\end{tabular}

Data presented as $L$ unless otherwise indicated. ERV Expiratory residual volume; FEV ${ }_{1}$ Forced expiratory volume in $1 \mathrm{~s}$; FRC Functional residual capacity; FVC Forced vital capacity; IC Inspiratory capacity; RV Residual volume; TLC Total lung capacity; VC Vital capacity

\section{REFERENCES}

1. Bishop WJ. The Early History of Surgery. The Trinity Press, London: Ebenezer Baylis;1960,64-5.

2. Roland (1499) De pulmonis sanarpot, liber III (cap) XXV. In: De Chavliae G. Cyrurgia, p 144

3. Morel-Lavelle A. Hernie du poumon. Bull Mem Soc Chir Paris $1847 ; 1: 75-195$

4. Hiscoe DB, Digman GJ. Types and incidence of lung hernias. J Thorac Cardiovasc Surg 1955;30:335.

5. Taylor DA, Jacobson HG. Posttraumatic herniation of the lung. Am J Roentgenol 1962;87:896-9.

6. Garrett JN, Braunstein PW. The seatbelt syndrome. J Trauma 1962:2:220-38.

7. Batra AK. Lung herniation after CPR. Crit Care Med 1986;14:595-6.

8. Fackeldey V, Junge K, Hinck D, et al. Repair of intercostals pulmonary herniation. Hernia 2003;7:215-7.

9. Busch T, Kley CW, Sirbu H, et al. Die incarcerierte traumatische intercostale lungenhernie. Chirurg 1999;70:946-8.

10. Sharma OP, Duffy B. Transdiaphragmatic intercostal hernia: Review of the world literature and presentation of a case. J Trauma 2001;50:1140-3.

11. Jacka MJ, Luison F. Delayed presentation of traumatic parasternal lung hernia. Ann Thorac Surg 1998;65:1150-1.

12. Emery RL, Beall DP, Ly JQ, et al. Congenital cervical lung herniation. AR Online 2003;32(7) < www.appliedradiology.com/ Issues/2003/07/Articles/Congenital-cervical-lung-herniation.aspx> (Accessed on November 7, 2011).

13. Thompson JS. Cervical herniation of the lung: Report of a case and review of the literature. Pediatr Radiol 1976;4:190-2.

14. Masmoudi S, Ghemissou N, Abid M, et al. Hernie pulmonaire traumatique chez un enfant. Arch Pediatr 2003;10:436-8.

15. Francois B, Desachy A, Cornu E, et al. Traumatic pulmonary hernia: Surgical versus conservative management. J Trauma 1998;44:217-9.

16. Rusca M, Carbognani P, Cattelani L, et al. Spontaneous intercostal pulmonary hernia. J Cardiovasc Surg (Torino) 2000;41:641-2.

17. Bowley DM, Boffard KD. Penetrating lung hernia with pulmonary evisceration: Case report. J Trauma 2001;50:560-1.

18. May AK, Chan B, Daniel T, et al. Anterior lung herniation: Another aspect of the seatbelt syndrome. J Trauma 1995;38:587-9.

19. Bastos R, Calhoon J, Baisden C. Flail chest and pulmonary contusion. Semin Thorac Cardiovasc Surg 2008;20:39-45.

20. Balci A, Eren S, Cakir O, Eren M. Open fixation in flail chest: Review of 64 patients. Asian Cardiovasc Thorac Ann 2004;12:11-5.

21. Ahmed Z, Mohyuddin Z. Management of flail chest injury: Internal fixation versus endotracheal intubation and ventilation. J Thorac Cardiovasc Surg 1995;110:1676-80.

22. Tanaka H, Yukioka T, Yamaguti Y, et al. Surgical stabilization of internal pneumatic stabilization? A prospective randomized study of management of severe flail chest patients. J Trauma 2002;52:727-32.

23. Saw E, Yokoyama T, Lee B, et al. Intercostal pulmonary hernia. Arch Surg 1976;111:548-51.

24. Lang-Lazdunski L, Bonnet P, Pons F, et al. Traumatic extrathoracic lung herniation. Ann Thorac Surg 2002;74:927-9.

25. Cernilia J, Lin J, Ott R, et al. A technique for repair of traumatic parasternal lung herniation. J Trauma 1995;38:935-6.

26. Slater M, Mayberry J, Trunkey D. Operative stabilization of a flail chest six years after injury. Ann Thorac Surg 2001;72:600-1. 